\title{
UNUSUAL VARIANTS OF FIBROADENOMA BREAST
}

Riddhi Jaiswal ${ }^{1}$, Urvashee Dwivedi² ${ }^{2}$ Sonal Ghaoghave ${ }^{3}$.

1. Assistant Professor, Department of Pathology, King George's Medical University.

2. Junior Resident, Department of Pathology, King George's Medical University.

3. Junior Resident, Department of Pathology, King George's Medical University.

\author{
CORRESPONDING AUTHOR: \\ Riddhi Jaiswal, \\ Department of Pathology, \\ King George's medical university, chowk, \\ Lucknow -226003. \\ E-mail: riddhiadvay@gmail.com
}

\section{ABSTRACT: UNUSUAL VARIANTS OF FIBROADENOMA BREAST DIAGNOSED ON CYTOLOGY}

Fibroadenomas are common benign breast tumours that display a characteristic morphology, although several epithelial and stromal variations exist which may pose a diagnostic difficulty. We are discussing a case series of four cases of benign fibroadenoma with morphological variations as observed on cytology smears in the department of Pathology, KGMU, Lucknow, UP. Juvenile fibroadenoma constitutes only $4 \%$ of the total fibroadenomas with incidence of $0.5 \%$ per year.

Another very rare histological finding is the presence of multinucleated giant cells throughout the stroma of a benign fibroadenoma, more commonly found incidentally within the interlobular stroma of breast tissue.

Similarly apocrine metaplasia has been found to be $28 \%$ in a case series (Arno Kuijper et.al) of 396 cases of fibroadenoma.

It is important to identify these variants as they may be misinterpreted as malignancy.

KEY WORDS: Fibroadenoma, variants, cytology

INTRODUCTION: Breast masses are uncommon in childhood. The majority of them are related to inflammation (infection or abscess) or benign tumors as fibroadenomas. Juvenile fibroadenoma is a rare clinical entity comprising $4 \%$ of the total fibroadenomas, of which giant juvenile fibroadenoma constitutes only $0.5 \% .^{1}$ Similarly fibroadenoma with apocrine metaplasia and multinucleated stromal giant cells occur rarely in the age group found in our series. We are presenting a series of 4 cases of fibroadenoma with these morphological variations each with case history, radiological and cytological findings.

\section{CASE HISTORY}

CASE NO .1: A 11 year old female patient (premenarchal) presented with lump in left breast for a duration of 4 months increasing progressively in size and not associated with pain. Family history, history of trauma, nipple discharge, fever, anorexia, or weight loss were absent. On local examination slightly tender, huge, nodular mass in left breast was seen, which was firm in consistency (Fig 1). The overlying skin was tense and shiny with prominent superficial veins. Left breast lump measured 10 x $8 \mathrm{~cm}$ and was not fixed to underlying structures. There was no discharge from the nipple, and axillary lymphadenopathy was absent. Routine hematological and biochemical examinations were 
within normal limits. Chest-X ray was normal. Ultrasonography was carried out which showed heterogenous parenchymal pattern suggestive of fibroadenoma.

Cytological findings showed cellular smears with large monolayered sheets and clusters of benign epithelial and myoepithelial cells in a background of haemorrhage. Individual epithelial and myoepithelial cells were uniform round to oval with bland nucleus and small amount of cytoplasm. Fair number of bare bipolar nuclei were also seen in background. Mitotic activity was absent. Based on cytological findings final diagnosis of Giant juvenile fibroadenoma of left breast was given.

\section{CASE NO.2}

A 17-year- old female patient presented with a lump in right breast for a duration of one and half years. Swelling was increasing gradually and progressively in size associated with mild pain and on and off fever. Menstrual and clinical history were unremarkable. On local examination a single mobile firm swelling with well defined margins was noticed in right breast measuring about $1.5 \mathrm{x} 1 \mathrm{~cm}$. Ultrasonography confirmed the presence of a $2 \mathrm{~cm}$ solid mass in the right upper quadrant.

Cytological findings showed cellular smears with monolayered sheets of benign ductal epithelial cells and myoepithelial cells which were round to oval, had uniform round nucleus with bland chromatin moderate eosinophilic cytoplasm. Fair no. of cyst macrophages ,bare bipolar nuclei and few multinucleated giant cells were also seen in background.(Fig 2) Based on cytological findings a final diagnosis of benign fibroadenoma with multinucleated stromal giant cells was given.

\section{CASE NO.3}

A 19- year- old female patient presented with lump in left breast for a duration of 8 months increasing slowly in size and not associated with pain. Family history, history of trauma, nipple discharge, fever, anorexia, or weight loss were absent. On examination it was about $2.5 \times 2 \mathrm{cms}$ in size, slightly tender to touch, freely mobile with normal overlying skin normal.

Cytology smears were cellular and show benign ductal epithelial cells arranged in large monolayered sheets and clusters in haemmorhagic background along with bare bipolar nuclei of myoepithelial cells. Sheets of apocrine cells having round nucleus and abundant Eosinophilic granular cytoplasm were also seen (Fig 3) Based on the cytological features diagnosis of fibroadenoma with apocrine changes was given.

\section{CASE NO 4:}

A 44- year- female patient presented with bilateral breast lump since 8-9 months. They were firm and freely mobile gradually progressing in size and not associated with pain, discharge, fever, weight loss, anorexia and any other lump in axilla. On examination $1.5 \times 1 \mathrm{~cm}$ lump was found in right and $0.5 \times 0.8 \mathrm{~cm}$ in left breast on ultrasound. Guided smears from both right and left breast were richly cellular and showed typical cytological features of fibroadenoma along with numerous stromal fragments (Fig 4). Based on these features, diagnosis of fibroadenoma with benign phylloides features -breast was given.

DISCUSSION: Juvenile fibroadenoma of the breast is defined as circumscribed, often large, breast mass usually occurring in adolescent females with stromal and epithelial hypercellularity but lacking the leaf-like growth pattern of phyllodes tumors. Diagnostic criteria for juvenile fibroadenoma are ${ }^{1,2}$ 


\section{CASE REPORT}

- Circumscribed and rarely multiple

- Biphasic stromal and epithelial process in which pericanalicular pattern is most common and lacks leaf-like growth pattern in uniformly hypercellular stroma. Fibrotic areas may be present

- Lack of atypical features in stroma-like periductal increase in cellularity, stromal overgrowth, cytologic atypia, and mitotic rate $>3 / \mathrm{hpf}$

- $\quad$ Frequent epithelial and myoepithelial hyperplasia

- Most patients' age is 10-20 years as in our case (11 years) with a mean age of 15 years.

The differentials of juvenile fibroadenoma include low-grade phyllodes tumor, virginal hypertrophy, and rarely lipoma, hamartoma, breast abscess, macrocyst, adenocarcinoma, and pseudoangiomatous stromal hyperplasia. Giant juvenile fibroadenoma is a benign tumor, and total excision of the lump with conservation of nipple and areola is the optimal treatment

In 1979 Rosen first described the presence of Multinucleated Stromal Giant Cells (MSGCs) in the breast, as an incidental finding in breast specimens from 14 patients with breast carcinoma and concluded that these cells represented a non-neoplastic and possibly reparative process ${ }^{3}$. All the patients were in perimenopausal age group (40-50 years). However, our case showed presence of multinucleated stromal giant cells in a teenage patient with benign breast disease. It was further suggested that Vimentin/CD34 positive fibroblast of mammary stroma could be the result of differentiation from a pluripotential mesenchymal precursor cell with the potential to differentiate toward several mesenchymal lines. ${ }^{4,5}$ The differential diagnosis includes the malignant phyllodes tumour and breast spindle cell tumour. 6

Fibroadenoma of the breast is associated with an elevated risk for invasive breast cancer, especially in case of complex changes and epithelial proliferations in adjacent tissue. ${ }^{7}$ Dupont et al ${ }^{8}$ found that the cumulative risk of invasive breast carcinoma in women with complex fibroadenomas (having one or more of the so-called complex features: epithelial calcifications, apocrine metaplasia), was 3.1 times that of women in the general population, compared with a relative risk of 1.89 times in women with noncomplex fibroadenomas. Kuijper A et al ${ }^{9}$ performed a study on 396 cases of fibroadenoma and found that apocrine metaplasia was the most frequent complex feature $(28.0 \%)$.

Fibroadenomas and phyllodes tumors may have similar cytological appearances and identical clinical and radiological appearance. However, a detailed study of cellularity of stromal fragments, and the proportion of spindle cells in the background are important features that may be helpful in differentiation. ${ }^{10}$

CONCLUSION: .Fine Needle Aspiration is an important tool in raising an alarm to the many lookalikes (for eg. Apocrine metaplasia and apocrine carcinoma) seen in the complex pathology of the breast, hence the smears must be screened significantly.

\section{REFERENCES:}

1. D. B. Nikumbh, S. R. Desai, P. S. Madan, N. J. Patil, and J. V. Wader Bilateral Giant Juvenile Fibroadenomas of Breasts: A Case Report ;Pathology Research International Volume 2011 (2011), Article ID 482046, 4 pages

2. A. Boothroyd and H. Carty, "Breast masses in childhood and adolescence. A presentation of 17 cases and a review of the literature," Pediatric Radiology, vol. 24, no. 2, pp. 81-84, 1994. 
3. Helen M Heneghan1, Sean T Martin1, Mary Casey2, Igdam Tobbia3, Fadel Benani3 and Kevin M Barry ; A diagnostic dilemma in breast pathology - benign fibroadenoma with multinucleated stromal giant cells, Diagnostic Pathology 2008, 3:33

4. Rosen P: Multinucleated mammary stromal giant cells - A benign lesion that simulates invasive carcinoma. Cancer 1979, 44(4):1305-1308

5. Berean K, Tron VA, Churg A, Clement PB: Mammary fibroadenoma with multinucleated stromal giant cells.American Journal of Surgical Pathology 1986, 10(11):823-827

6. Keeney GL, Ryška A, Reynolds C: Benign tumours of the breast with multinucleated stromal giant cells.Virchows Archiv: an international journal of pathology 2001, 439(6):768-77

7. Arno Kuijper, Ellen C.M. Mommers, Elsken van der Wall, and Paul J. van Diest;Histopathology of Fibroadenoma of the Breast: Am J Clin Pathol 2001;115:736-742

8. Dupont WD, Page DL, Parl FF, et al. Long-term risk of breast cancer in women with fibroadenoma. N Engl J Med 1994;331:10-15

9. Kuijper A, ECM Mommers ECM, van der Wall E, van Diest P J. Histopathology of Fibroadenoma of the Breast. Am J Clin Pathol 2001;115:736-74

10. Dusenbery D, Frable WJ. Fine needle aspiration cytology of phyllodes tumor. Potential diagnostic pitfalls. Acta Cytol. 1992; 36:215-21. Simi V, Moretti D, Iacconi P, Arganini M, Roncella M, Miccoli P, et al. Fine needle aspiration cytopathology of phyllodes tumor. Differential diagnosis with fibroadenoma. Acta Cytol. 1988;32:63-6

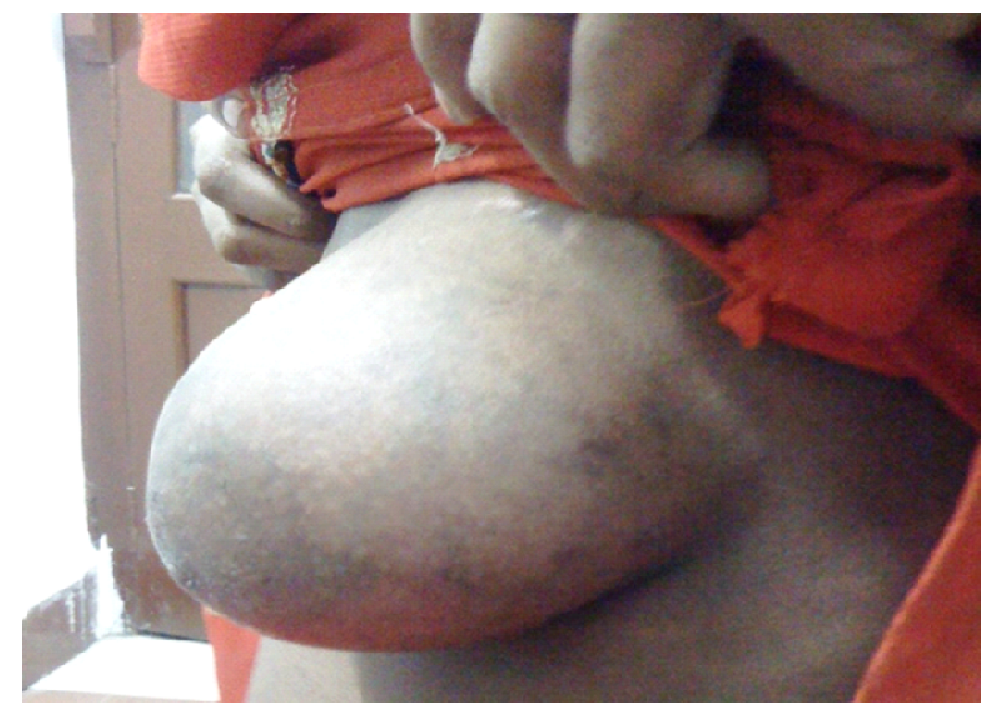

Picture 1: Gross image of giant fibroadenoma 


\section{CASE REPORT}

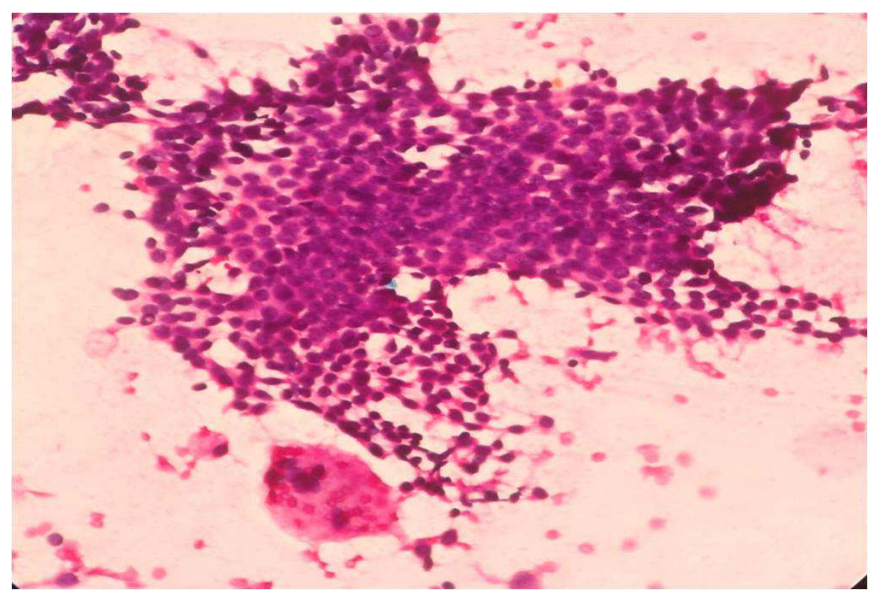

Picture 2: Fibroadenoma with stromal giant cells.

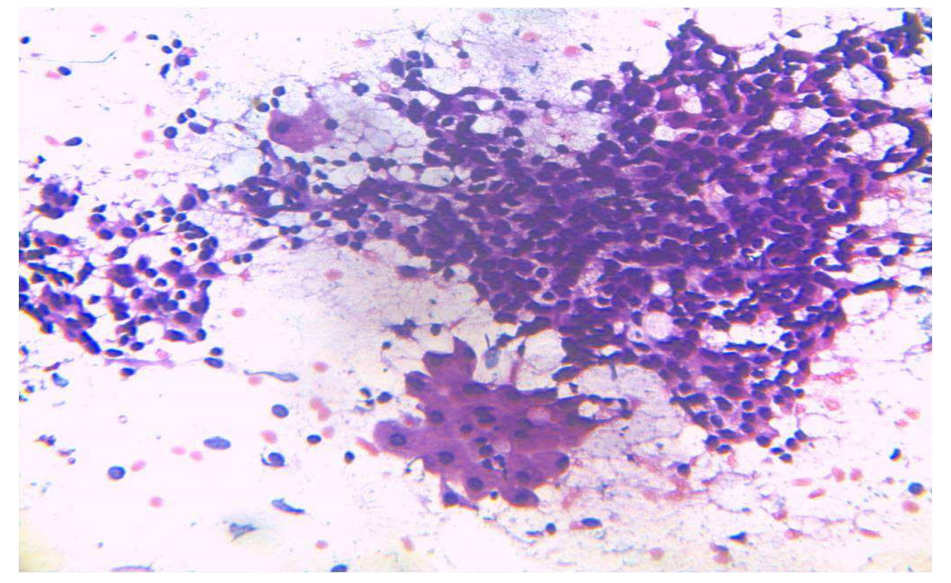

Picture 3: Fibroadenoma with apocrine metaplasia

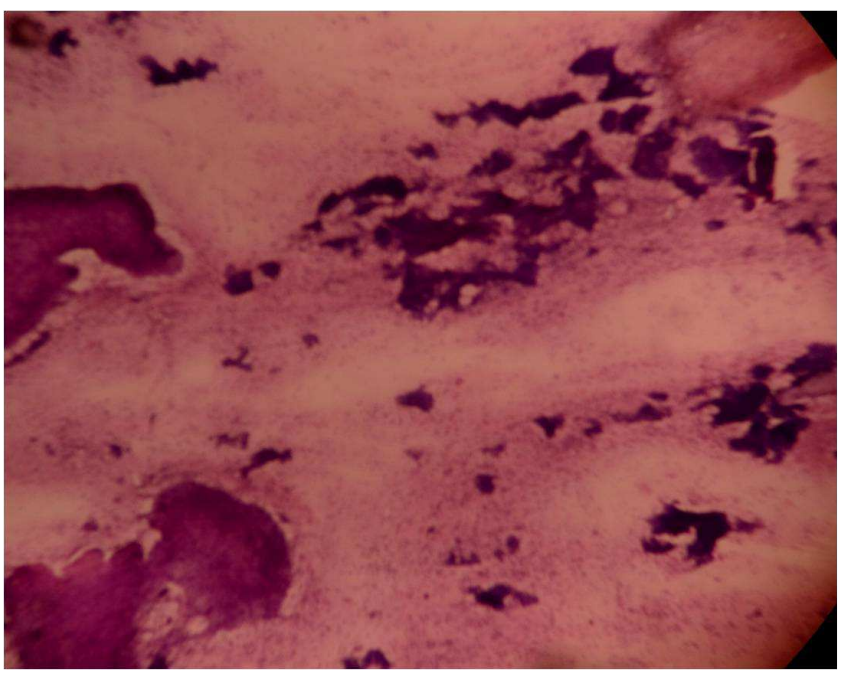

Picture 4: Fibroadenoma with stromal fragments. 